\title{
An audit of informed consent for cesarean section and instrumental delivery in a tertiary referral center in the United Kingdom
}

This article was published in the following Dove Press journal:

Clinical Audit

21 April 201 I

Number of times this article has been viewed

\author{
Kate Glennon' \\ Clare Tower ${ }^{2}$ \\ Joanna Gillham ${ }^{3}$ \\ Jenny Myers ${ }^{2}$ \\ 'St Mary's Hospital, Manchester \\ University, Manchester, UK; ${ }^{2}$ Maternal \\ and Fetal Health Research Centre, \\ St Mary's Hospital, Manchester, \\ UK; ${ }^{3}$ St Mary's Hospital, \\ Manchester, UK
}

\begin{abstract}
Purpose: To audit the process of informed consent for cesarean section (CS) and instrumental delivery (ID) in a tertiary referral center in the UK.

Design: The Royal College of Obstetricians and Gynaecologists (RCOG) guidelines on consent ${ }^{1}$ were used as audit standards. A retrospective questionnaire was used to assess patients' recall and views of the consent process. In total, 116 consent forms were audited ( $\mathrm{CS}=83$, instrumental delivery $=33$ ).

Findings: The consent forms complied with the auditable standards on consent for CS, in relation to documentation of the major risks of surgery. The majority of CS consent forms did not meet the standards in terms of documentation of the risk of laceration to baby or the possibility of hysterectomy. However, most women were questioned on consent between contractions, in accordance with the RCOG guidance on consent $(50 \% \mathrm{CS}$ deliveries and $68 \%$ instrumental deliveries). The patients who consented for elective CS, were more likely than emergency CS patients to be able to recall the risks explained.
\end{abstract}

Action: The findings of this audit indicate that the introduction of a standardized consent proforma would provide a structured approach to preoperative counselling and documentation.

Keywords: informed consent, cesarean section, instrumental delivery, patient recall, documentation

\section{Introduction}

Cesarean sections and instrumental deliveries (forceps and ventouse) are common procedures, performed in approximately $21 \%$ and $15 \%$ of births respectively. ${ }^{2}$ Informed consent is as important for these procedures as for other surgical operations. The issues of consent and adequate documentation are often debated in legal cases brought against members of the medical profession. Without the valid consent of a competent adult patient, the doctor cannot proceed with treatment. Information on impending surgical procedures may be helpful to patients and has proven to be a significant factor in coping with what may be perceived to be a threatening procedure. ${ }^{3}$

Legal and political considerations have played a role in the attention now focused on the issue of informed consent. The importance of patient-focused consent procedures emerged as a key theme in Bristol Royal Infirmary Inquiry Report. ${ }^{4}$ Informed consent is required by law, before any procedure is carried out on a patient and the General Medical Council recently published guidelines for doctors on consent and decision making. ${ }^{5}$
Clinical Lecturer, Maternal and Fetal Health Research Centre, 5th Floor, St Mary's Hospital, Oxford Road, Manchester MI3 9WL, United Kingdom Tel +44 (0) I6I 7016963

Fax +44 (0) I6I 70। 697I

Email jenny.myers@manchester.ac.uk
(C) 20II Glennon et al, publisher and licensee Dove Medical Press Ltd. This is an Open Access article which permits unrestricted noncommercial use, provided the original work is properly cited. 
The case of Sidaway in the House of Lords ${ }^{6}$ demonstrated the importance of providing patient information when obtaining consent. The case centered on a consultant anesthetist who gave a diclofenac suppository for postoperative pain to a patient. He did not seek the patient's specific consent preoperatively for use of the suppository. He was judged not to have obtained valid informed consent and was found guilty of serious professional misconduct. ${ }^{6}$

Pregnant women with capacity have the right to a full explanation of a procedure to allow their informed consent. The woman also has the right to refuse to consent to treatment even if this endangers her life or that of her unborn child. This was demonstrated in the case of "S". " The woman was diagnosed with pre-eclampsia requiring admission to hospital and induction of labor, but refused treatment because she did not agree with medical intervention in pregnancy. The Court of Appeal ruled that a woman may refuse consent to treatment in pregnancy despite the potential danger posed to her unborn child.

Consent and documentation in an emergency pose many challenges for doctors. They must be aware of the need for informed consent while considering the immediate nature of the situation. The difference between emergency and elective situations has been demonstrated in previous studies. A study of 734 patients undergoing elective or emergency surgery in obstetrics and gynecology was conducted by Akkad et al. ${ }^{8}$ Patients undergoing emergency surgery were less likely to have read or understood the consent form, and were more likely to report feeling frightened by signing it.

The Royal College of Obstetricians and Gynaecologists (RCOG) has provided guidance on consent for cesarean section (RCOG Consent Advice 7 [2009]). ${ }^{1}$ However, there is little guidance on informed written consent in instrumental deliveries. Two legal challenges, mounted in the US, demonstrate the confusion. In both cases the claimant maintained that they had not consented to the use of forceps. In Rizzo $v$ Schiller, ${ }^{9}$ the doctor claimed that he had informed the patient that he was going to use forceps immediately before he applied them, but that there was no time for a discussion. The supreme court of Virginia ruled that a discussion of the specific procedure ie, the use of forceps, was required. However, a contradictory ruling was given in a similar case of Sinclair $v$ Block. ${ }^{10}$ The court ruled that the use of forceps did not require specific informed consent. ${ }^{11}$

Given the importance of informed consent, this audit aimed to review practice relating to the documentation of informed consent, before emergency and elective obstetric procedures in an inner city maternity hospital.

\section{Methods}

The audit was approved by St Mary's audit department. A retrospective review of consent forms from 116 patients who had recently undergone a cesarean section (CS) or instrumental delivery (ID) in St Mary's hospital was performed. St Mary's Hospital is a large tertiary referral center in the North West of the UK, delivering approximately 5500 babies per annum. Medical staff were not made aware of the audit. The audit standards contained within the RCOG guidelines (RCOG 2009) were used to assess the written information on each consent form.

A questionnaire survey was conducted in the same patient group by a single investigator using a standard proforma and form of words, during office hours, while the women were inpatients on the post-natal ward (within 24 hours of delivery). The questionnaire was piloted among 10 patients and subsequently adjusted to include information on ethnicity and the grade of doctor who had obtained consent. Initially, women were asked to recall which procedural risks had been explained to them at the time of consent. Subsequently they were shown a written list of complications and asked to select which of the risks they remembered being mentioned. Patients who required an interpreter were not included in the study. The data were collected over 6 weeks during May to June 2008. Data were analyzed using Microsoft excel and SPSS.

\section{Results}

During the 6-week period of this audit, $108 \mathrm{CS}$ and 85 ID were performed at St Mary's Hospital. Data on 83 CS (76\% of total CS performed) and 61 ID (71\%) were collected. Most $(n=60,72 \%)$ CS were emergency procedures.

\section{Demographic data}

Of the women interviewed, 75 (56\%) were UK born, with women from Africa $(n=20)$, Europe $(n=16)$, and South Asia $(\mathrm{n}=24)$ also represented; $87(64 \%)$ of the patients were primigravid and the average length of labor was 9 hours (range 4-12 hours) for women who were delivered by emergency CS and 10.5 hours (range 5-12 hours) for women delivered by ID.

\section{Documentation}

All the patients delivered by CS had a written and signed consent form in the notes $(n=83)$, whereas only those delivered by ID who underwent a "trial of instrumental 
Table I Complications of cesarean section (CS) documented on consent forms

\begin{tabular}{|c|c|c|c|c|c|}
\hline Complication & $\begin{array}{l}\text { Consent forms with } \\
\text { risk documented } \\
(n=83)\end{array}$ & $\begin{array}{l}\text { Consented by } \\
\text { junior staff (ST I-5) } \\
(n=65)\end{array}$ & $\begin{array}{l}\text { Consented by senior } \\
\text { staff (ST6-7 and cons) } \\
(\mathrm{n}=22)\end{array}$ & $\begin{array}{l}\text { Elective CS } \\
(n=23)\end{array}$ & $\begin{array}{l}\text { Emergency CS } \\
(n=60)\end{array}$ \\
\hline Infection & $73(88 \%)$ & $58(86 \%)$ & 14 (87\%) & $20(90 \%)$ & $51(85 \%)$ \\
\hline Injury to viscera & $79(95 \%)$ & $63(94 \%)$ & $15(94 \%)$ & $23(100 \%)$ & $59(98 \%)$ \\
\hline Thrombosis & 74 (89\%) & 63 (94\%) & I3 (82\%) & $3(13 \%)$ & $9(15 \%)$ \\
\hline Repair of damage & $62(75 \%)$ & $54(65 \%)$ & $13(82 \%)$ & $19(85 \%)$ & 47 (79\%) \\
\hline Laceration/injury baby & 34 (41\%) & $13(40 \%)$ & $21(60 \%)$ & $9(39 \%)$ & $17(28 \%)$ \\
\hline Hysterectomy & $3(4 \%)$ & I $(0 \%)$ & $2(1 \%)$ & $3(13 \%)$ & 0 \\
\hline $\begin{array}{l}\text { Uterine rupture in } \\
\text { future pregnancies }\end{array}$ & $\mathrm{I}(1 \%)$ & 0 & 0 & I (4\%) & 0 \\
\hline $\begin{array}{l}\text { Risk of CS in future } \\
\text { pregnancies }\end{array}$ & $2(3 \%)$ & 0 & $2(1 \%)$ & $2(9 \%)$ & 0 \\
\hline
\end{tabular}

Notes: ST I-5, specialist training year I-5; ST 6-7, specialist training year 6-7; cons, consultant.

delivery in theatre" $(\mathrm{n}=23,38 \%)$ had evidence of written consent. Women who were delivered by instrumental delivery in the labor room $(n=32)$ had no record of verbal consent or the associated risks of ID documented in the notes. The majority of consent forms documented the intended benefit of performing a CS (96\%). Table 1 demonstrates that the major risks of CS were documented on the majority of consent forms, but that rarer complications were less likely to be documented. As expected, consent forms for elective procedures were more complete than those for emergencies (Table 1).

The majority of the consent forms for CS had been completed by junior doctors (78\%). A total of 45 (54\%) consent forms were completed by ST1-2 doctors (2-4 years post qualification), 20 (24\%) by ST3-5 doctors (4-7 years post qualification), and 22 (26\%) by senior trainees or consultants. Seniority of doctor did not alter the likelihood of documentation of the major risks of infection and injury to viscera. As shown in Table 1, junior staff were less likely to mention fetal laceration as a risk $(P=0.03$, chi squared $)$.

\section{Patient recall}

For women undergoing emergency procedures during labor, most $(50 \%$ ID, 70\% CS) recalled that consent had been

Table 2 Analysis of recall of risk unprompted: elective vs emergency cesarean section (CS) and delivery room vs theater instrumental delivery (ID)

\begin{tabular}{|c|c|c|c|}
\hline \multicolumn{2}{|c|}{ Type of delivery (n) } & \multirow{2}{*}{$\begin{array}{l}\text { No risk } \\
\text { recalled, n (\%) } \\
4(17 \%)\end{array}$} & \multirow{2}{*}{$\begin{array}{l}\text { At least one risk } \\
\text { recalled, } n(\%) \\
19(82 \%)\end{array}$} \\
\hline CS & Elective (23) & & \\
\hline & Emergency (60) & $23(38 \%)$ & $37(62 \%)$ \\
\hline \multirow[t]{2}{*}{ ID } & Delivery room (32) & $22(69 \%)$ & II (34\%) \\
\hline & Theater (28) & $18(64 \%)$ & $10(3 \%)$ \\
\hline
\end{tabular}

obtained between contractions. Twenty per cent of women $(\mathrm{n}=17)$ delivered by $\mathrm{CS}$ and $7 \%(\mathrm{n}=4)$ of women delivered by forceps or ventouse were unable to recall the timing of the consent.

Tables 3 and 4 show the risks recalled by patients. Unprompted, patients undergoing emergency CS were less likely to be able to recall the risks documented on the consent form: 37/60 (62\%) emergency CS compared with 19/23 (82\%) elective CS patients $(P<0.05$, chi-squared) were able to recall the risks explained (Table 3 ).

As with patients who had undergone a CS, the patients who had an ID were asked which risks they could recall (Table 4). Unprompted, 66\% (40/61) undergoing ID were unable to recall any of the risks explained to them. In contrast, $33 \%(n=27)$ of patients delivered by CS (both emergency and elective) could not recall any risks documented on the consent form. The most common risk that was recalled was swelling or marks on the baby's head after the use of forceps or ventouse. This was recalled, unprompted, by 15 (25\%) of those surveyed and by 25 (71\%) when prompted (Table 4).

\section{Discussion}

This audit demonstrates the inadequate documentation of consent for ID and CS in a busy, city-center maternity hospital. Current literature suggests that this inadequate documentation is mirrored in other centers. ${ }^{12}$ Yet, the General Medical Council guidelines encourage doctors to actively engage patients in discussions, and advises doctors to work "in partnership" with their patients. ${ }^{13}$

Women undergoing emergency procedures were less able to recall risks than those undergoing elective operations. Particular inadequacies highlighted were that the provision of consent by women undergoing ID in the delivery room was 
Table 3 Recall of risk for emergency and elective cesarian section (CS) deliveries, $\mathrm{n}$ (\%)

\begin{tabular}{lllll}
\hline Risk & \multicolumn{2}{l}{ Elective CS $(\mathbf{n}=\mathbf{2 3})$} & & Emergency CS $(\mathbf{n}=60)$ \\
\cline { 2 - 3 } & Unprompted & Prompted & Unprompted & Prompted \\
\hline Bleeding & $15(65 \%)$ & $23(100 \%)$ & $14(23 \%)$ & $54(90 \%)$ \\
Transfusion & $3(13 \%)$ & $22(96 \%)$ & $8(13 \%)$ & $45(76 \%)$ \\
Infection & $7(30 \%)$ & $22(96 \%)$ & $13(22 \%)$ & $52(87 \%)$ \\
Injury viscera & 0 & $23(100 \%)$ & $2(3 \%)$ & $5693 \%)$ \\
Injury baby & 0 & $9(39 \%)$ & $3(5 \%)$ & $17(28 \%)$ \\
Thrombosis & $1(4 \%)$ & $18(80 \%)$ & $1(1 \%)$ & $9(15 \%)$ \\
Future CS & 0 & $5(25 \%)$ & 0 & $6(10 \%)$ \\
\hline
\end{tabular}

not documented in the notes, and that women delivered by forceps or ventouse were unable to recall the risks explained to them, suggesting that verbal consent was not "informed". This may reflect the urgent nature of some of these deliveries. A previous report also identified poor documentation of consent for ID. ${ }^{12}$ A review of 100 case notes found that the documentation of any maternal or neonatal risks was $3 \%$ and $0 \%$, respectively.

Documentation of the risks associated with CS was better in terms of information on the intended benefits and the major and most common complications. The RCOG guidelines on consent for $\mathrm{CS}^{1}$ recommend that women are also informed of the serious maternal risks of CS such as hysterectomy, yet only $4 \%$ of the consent forms audited documented this risk. This audit also highlighted a failure to inform women of the risks of fetal laceration, because $60 \%$ of the forms did not include this risk. These risks should be discussed in the context of promoting the ethical principle of autonomy. However, since the risk of hysterectomy is below $1 \%,{ }^{1}$ it may be reasonable for doctors not to disclose this unless the clinical situation increases the risk of hysterectomy (eg, several previous CS). Following Sidaway v Bethlem and Maudsley Hospitals, ${ }^{6}$ it is deemed acceptable practice not to disclose a risk occurring with a frequency of less than $1 \%$. However, research suggests that some patients wish to be informed of "significant" risks, no matter how rarely they occur ${ }^{14}$ and a hysterectomy following CS would be considered a "significant" risk. In this audit, the risk of fetal laceration was less likely to be documented on emergency consent forms despite the fact that the incidence

Table 4 Recall of risk for instrumental delivery, prompted and unprompted

\begin{tabular}{lll}
\hline Risk & Unprompted, n (\%) & Prompted, n (\%) \\
\hline Bleeding & $9(15 \%)$ & $32(52 \%)$ \\
Forceps marks & $15(25 \%)$ & $33(79 \%)$ \\
Swelling & $15(25 \%)$ & $25(71 \%)$ \\
Episiotomy & $3(5 \%)$ & $32(53 \%)$ \\
Anal damage & 0 & $9(26 \%)$ \\
Perineal infection & 0 & $7(1 \%)$ \\
\hline
\end{tabular}

of fetal laceration is significantly higher during emergency CS compared with elective procedures. ${ }^{15}$

The majority of patients in this survey remembered staff explaining the procedure to them and believed that the procedure was explained between contractions; this is in line with the RCOG Clinical Governance advice guidelines. Emergency CS patients were less likely than elective CS to be able to recall the risks documented, indicating the effect of a stressful situation on obtaining informed consent. In addition, the majority of patients undergoing an ID (verbal consent only) could not recall any risks being explained unless prompted. This suggests that where a written consent form is provided, risk recall is improved. In a study of informed consent prior to epidural in labor, the majority of women reported that written consent would help them "remember and appreciate the different anesthetic options, risks, and procedures". ${ }^{16}$ Only a minority of patients who underwent an ID could recall the risk of anal sphincter damage being discussed and only half of the women asked could recall the risk of an episiotomy being mentioned. Perineal trauma is a common and significant risk associated with ID and can be associated with considerable morbidity after the procedure. It therefore seems prudent that this should be discussed before the procedure if possible. The most striking finding of this audit, however, is that recall of risks was very poor whatever the mode of consent. It is difficult to know how this recall can be improved, particularly in an emergency setting, but clearly this area needs more attention, and perhaps medical and midwifery staff should spend more time during the antenatal period discussing the potential complications associated with different modes of delivery.

Because this audit was restricted to a 6 -week period, the number of consent forms that could be reviewed was limited. In addition, including women who required an interpreter was not possible. It is likely that communication difficulties with patients whose first language is not English would strongly influence the effectiveness of the consent process. The use of analgesia in labor may also have affected recall, because those who had an effective epidural may have had better recall than those who did not, or those who did not use opiates for pain 
relief. The audit was not powered to look at the effect of different times of delivery but this may also affect the results.

\section{Conclusion}

Adequate documentation is essential in all aspects of medicine. Inadequate documentation is frequently identified as being deficient in medical complaints and litigation cases. This audit highlighted regular deficiencies in documentation, particularly in relation to the consent of women undergoing instrumental delivery. Staff education and a re-audit are necessary to ensure that the documentation complies with the standards of practice set by the RCOG.

The significant difference in risk recall identified among women undergoing CS compared with instrumental delivery needs to be addressed, and large deficiencies in recall suggest that these patients are not best served by the current consent process. Given that the purpose of informed consent is to ensure that patients fully understand, and agree to, the proposed medical intervention, the findings presented here suggest that written consent is more likely to result in comprehension of the risks and benefits described.

\section{Dissemination of results}

The findings of this audit have been presented at a multidisciplinary meeting in the department and guidelines are being reviewed by the clinical governance team. Specific training relating to consent has now been incorporated in the junior doctors' induction program.

\section{Recommendations}

- Clear departmental guidance on minimal requirements for obtaining and documenting verbal consent prior to instrumental delivery.

- Clear hospital specific auditable standards for documentation and a system for accrediting consent forms should be established, and these should be regularly reviewed and updated.

- Consideration should be given to developing standardized consent forms for common obstetric procedures including instrumental delivery, in line with the RCOG guidance on "Obtaining valid Consent" (RCOG 2008) ${ }^{17}$

Clinical Audit

\section{Publish your work in this journal}

Clinical Audit is an international, peer-reviewed, open access journal focusing on the processes and outcomes of clinical audit in any area of healthcare. All aspects of patient care are addressed within the journal and practitioners from all disciplines are invited to submit their work. Areas covered include: Publication of audits; How an audit has changed practice; Practical tips on

Submit your manuscript here: http://www.dovepress.com/clinical-audit-journal and Consent for Cesarean section (RCOG Consent Advice Number 7 2009). ${ }^{1}$

- Repeat of this audit to assess improvement in recall and documentation within 2 years.

\section{Disclosure}

The authors report no conflicts of interest in this work.

\section{References}

1. Royal College of Obstetricians and Gynaecologists. Cesarean Section. Consent Advice 7. RCOG; 2009.

2. National Health Maternity Statistics 2008/09. http://www.ic.nhs.uk/ statistics-and-data-collections/hospital-care/maternity/nhs-maternitystatistics-2008-2009. Accessed May 1, 2008.

3. Coulter A, Entwistle D, Gilbert D. Sharing decisions with patients: is the information good enough? BMJ. 1999;318(7179):318-312.

4. Bristol Royal Infirmary Enquiry. Learning from Bristol: the report of the public inquiry into children's heart surgery at the Bristol Royal Infirmary 1984-1995. Bristol Royal Infirmary; 2001.

5. General Medical Council. Consent: patients and doctors making decisions together. London: General Medical Council; 2008.

6. Sidaway v Governors of the Bethlem Royal and Maudsley Hospital, AC 871 (1985).

7. St George's Healthcare NHS Trust v S; Rv Collins and others, ex parte $S$ [1998] 3 All ER 673

8. Akkad A, Jackson C, Kenyon S, Dixon-Woods M, Taub N, Habiba M. Informed consent for elective and emergency surgery: questionnaire study. BJOG. 2004;111(110):1133-1138.

9. Rizzo v Schiller 445 SE2d 153 (1994).

10. Sinclair by Sinclair v Block 633 A.2d 1137 (1993).

11. Maclean A. Consent, sectionalisation and the concept of a medical procedure. J Med Ethics. 2002;28:249-254.

12. Nichols CM, Pendlebury LC, Jennill J. Chart documentation of informed consent for operative vaginal delivery: is it adequate? South Med J. 2006;99(12):1337-1339.

13. General Medical Council. Consent: patients and doctors making decisions together. London; 2008.

14. Skene L, Smallwood R. Informed consent: lessons from Australia. $B M J$. 2002;324(1):39-41.

15. Dessole S, Cosmi E, Balata A, et al. Accidental fetal lacerations during cesarean delivery: experience in an Italian level III university hospital. Am J Obstet Gynaecol. 2004;191(5):1673-1677.

16. Gerancher JC, Grice SC, Dewan DM, Eisenach J. An evaluation of informed consent prior to epidural analgesia for labor and delivery. Int J Obstet Anesth. 2000;9(3):168-173.

17. Royal College of Obstetricians and gynaecologists. Clinical Governance Advice No 6: Obtaining Valid Consent, 2008.

\section{Dovepress}

how to do audits and to avoid pitfalls; How audits have changed patient care; Calls and justifications for new audits. The manuscript management system is completely online and includes a very quick and fair peer-review system, which is all easy to use. Visit http://www.dovepress.com/ testimonials.php to read real quotes from published authors. 